\title{
STUDY ON THE EFFECTS OF WOOD FLOUR GEOMETRY ON PHYSICAL AND MECHANICAL PROPERTIES OF WOOD-PLASTIC COMPOSITES
}

\author{
Azar Khonsari ${ }^{1}$, Hamid R Taghiyari ${ }^{2, \wedge}$, Ali Karimi ${ }^{1}$, , Mehdi Tajvidi $^{4}$
}

\begin{abstract}
The present study is focused on the effects of the shape and size of Fagus orientalis wood flour on physical and mechanical properties of HDPE based wood plastic composites (WPC). Variables included two mesh sizes (20 and 60), as well as five different contents of ground shavings $(0,25,50$, 75 , and $100 \%$ ) mixed with sawdust; totally 10 treatments. HDPT content was $40 \%$ in all formulations. Panels were compression molded and physical and mechanical tests were carried out in accordance with ASTM D2240 standard specifications. Results showed that mesh size can only significantly affect the hardness in the studied wood-plastic composites. On the other hand, increasing the proportion of the ground shavings possessing higher aspect ratio $(1 / \mathrm{d})$ increased both flexural strength and hardness. This increasing effect however was not observed for ground shavings beyond $50 \%$. It was also concluded that while the addition of ground shavings up to $50 \%$ could improve the mechanical properties, higher proportions would reduce some of the properties, particularly the impact strength. In was concluded that the panel made of 50\% wood flour combined with $50 \%$ ground shavings exhibited overall suitable properties for most applications.
\end{abstract}

Keywords: Fagus orientalis, ground shavings, high density polyethylene, mesh size, sawdust, wood composite materials.

\section{INTRODUCTION}

Wood is an orthotropic natural material, which is frequently modified by engineering processes to give stiffness or homogeneous mechanical properties because few species offer radial and axial uniformity in their structure (Ayrilmis et al. 2007, Akhtari et al. 2012, Papadopoulos 2012, Taghiyari et al. 2012). Composite-boards, however, offer the advantages of a homogeneous structure and the use of raw materials without restrictions as to the shape and size (Eshaghi et al. 2013). Most conventional wood composite panels are currently produced using a formaldehyde based resin as the binder. There are many studies focusing on finding methods to limit formaldehyde emission and improve the properties of conventional wood composites (Stockel et al. 2012, Valenzuela et al. 2012). Wood-plastic composites (WPCs) offer the best homogeneity as well as higher resistance to biological deterioration agents, water and moisture, and therefore, can be substituted for solid wood in today's building structures and industrial applications if certain structural limitations are addressed. These materials have economic advantages because of variety in raw materials, as well as better natural durability in comparison with solid wood (Tajvidi et al. 2008). They are also more environmentally preferred due to no-added-formaldeyde in their formulations. Use of natural fibers in composites can improve mechanical properties while reducing costs and weight (Lee et al. 2001).

\footnotetext{
Department of Wood and Paper Science and Technology, Faculty of Natural Resources, The University of Tehran, Tehran, Iran.

Wood Science \& Technology Dept., Faculty of Civil Engineering, Shahid Rajaee Teacher Training University, Tehran, Iran

Department of Biocomposite Technology, Institute of Tropical Forestry \& Forest products (INTROP), University Putra Malaysia (UPM),

Kuala Lumpur, Malaysia.

${ }^{4}$ School of Forest Resources, University of Maine, Orono, ME, USA

^ Corresponding author: htaghiyari@srttu.edu

Received: 05.05.2014 Accepted: 09.11.2014
} 
Scrap-wood-derived fillers have been increasingly being used in WPCs in recent years. They have several advantages over their inorganic counterparts such as lower density and lower volumetric cost. They are also less abrasive to processing equipment and are derived from a renewable resource. The shape, size, and species though are quite variable and therefore would provide different properties. They may be in the shape of particles, fiber bundles, or even single fibers. One of the most commonly used wood-derived fillers is wood flour. Wood flour is commercially produced from postindustrial sources such as planer shavings and sawdust. Sawdust is generally used as wood flour in WPCs, adding to its hardness, but not considerably affecting its strength; while other particles having higher aspect ratios (1/d) are used as reinforcing elements that increase nearly all mechanical properties. At a particular length of particles, stress is transferred from the matrix to the particles. In fact, the interfacial interaction between the polymer and wood fibers was reported to improve with a reduction in wood fiber length, resulting in an increase in modulus of rupture and toughness (Gallagher \& McDonald 2013). The process of stress-transfer is complete if there is good bonding between the particles and the matrix. Coupling agents are therefore essential to ensure suitable bond formation between the particles and the matrix. Coupling agents may physically or chemically improve the bonds (Myers et al. 1991). Toughness was reported to increase upon addition of MAPE (Maleic Anhydride Polyethylene) as well (Gallagher \& McDonald 2013).

The two main characteristics of wood flour that have been studied so far are species and mesh size. Berger and Stark examined the effects of species on the properties of wood flour reinforced thermoplastics (Berger and Stark 1997). It was also found that mesh size significantly affected the properties of polypropylene filled with nominal 20- and 40-mesh wood flour (Myers et al. 1991). Changes on the basis of particle size were reported in a study of four sizes of oil palm wood flour used as filler at different concentrations of polypropylene (Zaini et al. 1996). However, the latter two papers report conflicting trends for flexural and tensile data. Stark and Berger also studied the effect of the size of particles on properties of wood-flour reinforced polypropylene composites (Stark and Berger 2003). Tensile and flexural modulus were both positively influenced by fiber length (Lee et al. 2001). However, the modulus of rupture (MOR) was shown to increase with a reduction in wood fiber size; modulus of elasticity increased though (Gallagher \& McDonald 2013).

Wood plastic composites are predominantly produced using an extruder in a single compounding process or using an extruder and an in line injection molder in a two-step process. Flat pressed wood plastic composites however have the advantage of the availability of hot presses in conventional wood composite manufacturing facilities and the ability to readily control the density of the panel. A number of studies have been carried out on these types of wood plastic composites (Chaharmahali et al. 2005, 2007,2008 , 2010) but little or no study is carried out on a mixture of sawdust and shavings as two important wood flour sources at different proportions in flat pressed WPCs. Effects of particle size and geometry as a function of sawdust-shaving ratio is the main focus of the present study. 


\section{EXPERIMENTAL}

\section{High Density Polyethylene}

High density polyethylene (HDPE), grade name HD-3840UA, was purchased from Tabriz Petrochemical Company in the form of powder. Its melt flow index was 2,5-4 g/10 min, and it had a density of $0,933 \mathrm{~g} / \mathrm{cm}^{3}$.

\section{Maleic Anhydride Polyethylene}

Maleic anhydride polyethylene (MAPE) was BORECOAT ME0433 with a density of $0,934 \mathrm{~g} / \mathrm{cm}^{3}$. Ninety percent of MAPE particles were smaller than $350 \mu \mathrm{m}$.

\section{Beech Sawdust and Ground Shavings}

Wood flours were procured from the workshop of Department of Wood and Paper Science and Technology, Faculty of Natural Resources, University of Tehran. Two types of wood flours were used:

1- Beech sawdust;

2- Beech shavings were ground by a laboratory hammer mill down to a nominal mesh size of 20 .

Sawdust and ground shavings were passed through laboratory sieves. The fractions between 20 and 40 mesh screens, as well as those between 60 and 100 mesh screens were used in the production of composite panels.

\section{Microscopic Observation}

Samples of sawdust as well as ground shavings, both at 20 and 60 meshes were directly observed by an optical microscope at a $40 \times$ magnification. No primary preparation was carried out for microscopic imaging.

\section{Wood Flour Preparation}

Sawdust and ground shavings of beech were dried in an oven for 24 hours at $103 \pm 5^{\circ} \mathrm{C}$. To prevent any moisture absorption from the air, they were kept in plastic bags.

\section{Mixing Process}

Dried wood flours and polyethylene powder were mixed based on their weight ratios (Table 1). Once the ingredients of each composite formulation were weighed to a $0,01 \mathrm{~g}$ precision, they were manually mixed and again kept in plastic bags before the compression molding process. Care was taken to mix the ingredients as homogenously as possible.

Table 1. WPC formulations of the 10 treatments in the present study.

\begin{tabular}{|c|c|c|c|c|c|c|}
\hline \multirow[b]{2}{*}{ Treatment } & \multirow[b]{2}{*}{ Code } & \multirow[b]{2}{*}{ Mesh Size } & \multicolumn{2}{|c|}{$\begin{array}{l}\text { Wood Flour formulation } \\
\text { (totally } 58 \% \text { ) }\end{array}$} & \multirow[b]{2}{*}{$\begin{array}{c}\text { HDPT } \\
\text { Content }(\%)\end{array}$} & \multirow[b]{2}{*}{$\begin{array}{l}\text { MAPH } \\
(\%)\end{array}$} \\
\hline & & & $\begin{array}{c}\text { Sawdust } \\
(w t \%)\end{array}$ & $\begin{array}{c}\text { Ground } \\
\text { Shavings } \\
(w t \%)\end{array}$ & & \\
\hline 1 & $\mathrm{~A}$ & 20 & 100 & 0 & 40 & 2 \\
\hline 2 & B & 20 & 75 & 25 & 40 & 2 \\
\hline 3 & $\mathrm{C}$ & 20 & 50 & 50 & 40 & 2 \\
\hline 4 & $\mathrm{D}$ & 20 & 25 & 75 & 40 & 2 \\
\hline 5 & $\mathrm{E}$ & 20 & 0 & 100 & 40 & 2 \\
\hline 6 & $\mathrm{a}$ & 60 & 100 & 0 & 40 & 2 \\
\hline 7 & $\mathrm{~b}$ & 60 & 75 & 25 & 40 & 2 \\
\hline 8 & $\mathrm{c}$ & 60 & 50 & 50 & 40 & 2 \\
\hline 9 & $\mathrm{~d}$ & 60 & 25 & 75 & 40 & 2 \\
\hline 10 & $\mathrm{e}$ & 60 & 0 & 100 & 40 & 2 \\
\hline
\end{tabular}




\section{WPC Production}

The composite panels were produced using hot press compression molding. Panels were $25 \times 25 \mathrm{~cm}^{2}$, and $1 \mathrm{~cm}$ in thickness. Press temperature was $180^{\circ} \mathrm{C}$ and pressing time was $25 \mathrm{~min}$. After hot pressing, panels were kept in a cold press for $5 \mathrm{~min}$. Three replications were produced for each composite formulation so that the total number of panels produced was 30. Panels were kept at room conditions for 1 week before specimens were cut for physical and mechanical tests.

\section{Mechanical Properties}

\section{Three-Point Bending Test}

Three-point static flexural tests were performed according to the ASTM D7031-04 specification. Nominal sizes of the specimens were $20 \times 3 \times 1 \mathrm{~cm}$, with loading speed of $10 \mathrm{~mm} / \mathrm{min}$. Modulus of rupture (MOR) as well as modulus of elasticity (MOE) were calculated. Six samples of each treatment were tested using INSTRON 4486 test machine, equipped with a $10 \mathrm{kN}$ load cell.

\section{Impact Strength}

Impact strength tests were performed according to the ASTM D256; unnotched impact strength of the specimens was measured in terms of $\mathrm{J} / \mathrm{cm}$ using a pendulum-type impact testing machine. The nominal dimensions of the specimens were $8 \times 1,5 \times 1 \mathrm{~cm}$, with six replications.

\section{Hardness}

Hardness was measured according to ASTM D2240 standard specification; a needle hardness measuring apparatus was used in terms of SHORE D, with six replications.

\section{Physical Properties}

Density was the same in all 10 treatments in order to provide easier comparison $(0,93 \pm 0,01 \mathrm{~g} /$ $\left.\mathrm{cm}^{3}\right)$. Density variations are expected in hot pressed WPCs. Hence effort was made to select specimens of similar density in all experiments. Physical properties of long term thickness swelling and water absorption (1400 hours) were measured in accordance with ASTM D1037 (Equations 1 and 2). Nominal dimensions of specimens were $6 \times 3 \times 1 \mathrm{~cm}$ with 6 replications for each treatment. Specimens were weighed to a precision of $0,01 \mathrm{~g}$ by a digital scale. Thickness swelling was monitored at 5 points of each single specimen by a $0,01 \mathrm{~mm}$ precision micrometer; the 5 points included one in the center of the specimen, and four other points at every corner; the average of 5 points is reported.

$$
\text { Thickness Swelling }=\frac{T_{X}-T_{0}}{T_{0}} \times 100
$$

where $T_{x}$ and $T_{0}$ are thickness (mm) at time $x$ and the initial thickness (mm), respectively.

$$
\text { Water Absorption }=\frac{M_{X}-M_{0}}{M_{0}} \times 100
$$

where $M_{x}$ and $M_{0}$ are weight (g) at time $x$ and dry weight (g), respectively.

\section{Water Diffusion Coefficient}

Water uptake values were plotted versus root time/thickness values and the gradient of the linear portion of the curves $(m)$ were determined. Water diffusion coefficients of all formulations were then calculated using Equation 3:

$$
D=\pi\left[\frac{m h}{4 M_{\infty}}\right]^{2}\left[1+\left(\frac{h}{L}\right)+\left(\frac{h}{n}\right)\right]^{2}
$$


where $D$ is the water diffusion coefficient corrected for edge effect; $m$, the gradient of linear portion of the water content against root time/thickness curve; $M_{\infty}$, the equilibrium moisture content, which is the value of the water absorbed such that there is no further change in the water absorption with time; $h$, the thickness; $L$, the length; and $n$ is the width (Tajvidi et al. 2006).

\section{Statistical Analysis}

Statistical analysis was conducted using SPSS software program, version 15. One-way ANOVA was performed to conclude significant difference at $95 \%$ confidence level. Grouping was then made between treatments using the Duncan's test. Hierarchical cluster analysis, including dendrogram and using Ward's method with squared Euclidean distance intervals, was carried out within SPSS/18 (2010). Cluster analysis was performed to find similarities and dissimilarities between treatments based on more than one property simultaneously. The scaled indicator in each cluster analysis shows how much treatments are similar or different; lower scale numbers show more similarities while higher ones show dissimilarities.

\section{RESULTS and DISCUSSION}

\section{Microscopic Image Analysis}

Length and thickness of 60 particles of each wood flour treatments were measured. Results proved significant difference among the different aspect ratios (1/d) (Table 2) and shapes (Figure 1).

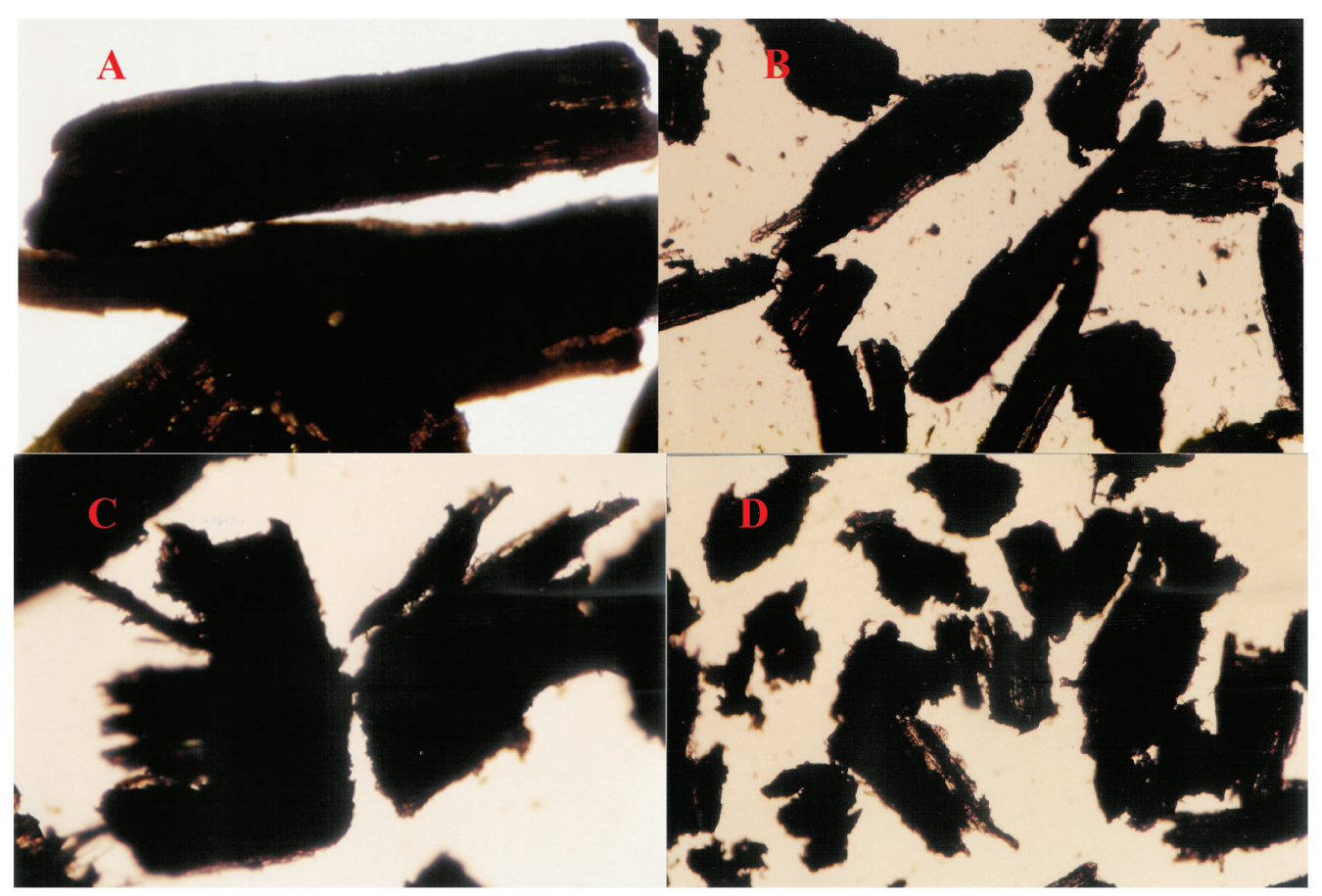

Figure 1. Micrographs of different wood particles; A. ground shaving at 20 mesh, B. ground shaving at 60 mesh, C. sawdust at 20 mesh, D. sawdust at 60 mesh (40× magnification). 
Table 2. The mean values of aspect ratios of different wood flours in the present study.

\begin{tabular}{|c|c|c|c|c|}
\hline $\begin{array}{l}\text { Type of } \\
\text { Wood } \\
\text { Flour }\end{array}$ & $\begin{array}{l}20 \text { mesh } \\
\text { Sawdust }\end{array}$ & $\begin{array}{l}20 \text { mesh } \\
\text { Ground } \\
\text { Shaving }\end{array}$ & $\begin{array}{l}60 \text { mesh } \\
\text { Sawdust }\end{array}$ & $\begin{array}{l}60 \text { mesh } \\
\text { Ground } \\
\text { Shaving }\end{array}$ \\
\hline $\begin{array}{l}\text { Aspect } \\
\text { Ratio (1/d) }\end{array}$ & $\begin{array}{c}1,58 \\
(0,15)^{*}\end{array}$ & $\begin{array}{c}2,57 \\
(0,24) \\
\end{array}$ & $\begin{array}{c}2,68 \\
(0,12) \\
\end{array}$ & $\begin{array}{l}4,44 \\
(0,2) \\
\end{array}$ \\
\hline
\end{tabular}

*Figures in parenthesis are the standard deviations.

\section{Mechanical Properties}

\section{Modulus of Rupture (MOR)}

Although not significantly different, results of MOR tests showed an increase when shaving content was increased in the formulation regardless of the mesh sizes 20 or 60 (Figure 2). Increase in MOR as a result of increase in the aspect ratio of wood flour was also reported in other studies (Stark and Rowlands 2003). Higher aspect ratios provided better transfer of stress to the particles in the matrix, resulting in higher MOR.

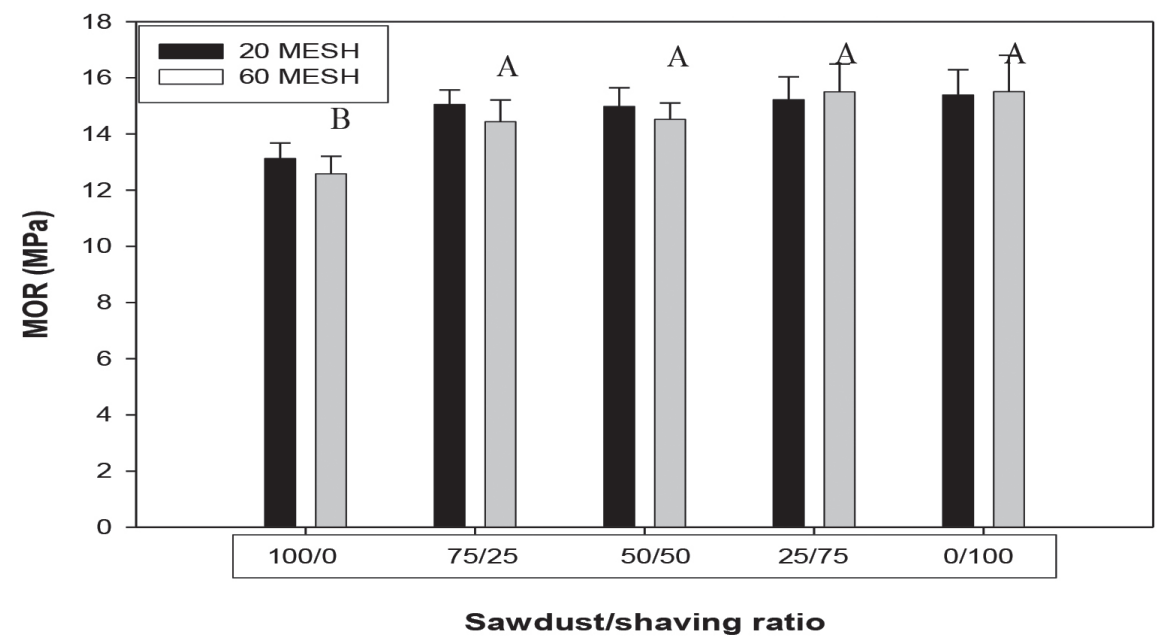

Figure 2. Effects of different wood flour formulations (\%) and mesh sizes on MOR values (letters on columns represents the Duncan groupings).

\section{Modulus of Elasticity (MOE)}

Results showed an increasing trend in MOE as wood shavings content increased to reach to its maximum value at $100 \%$ (Figure 3). The same increasing trend was reported by Stark and Rowlands (Stark and Rowlands 2003). This increase in MOE values can also be contributed to the better transfer of stress to the shavings, due to their higher aspect ratios. 


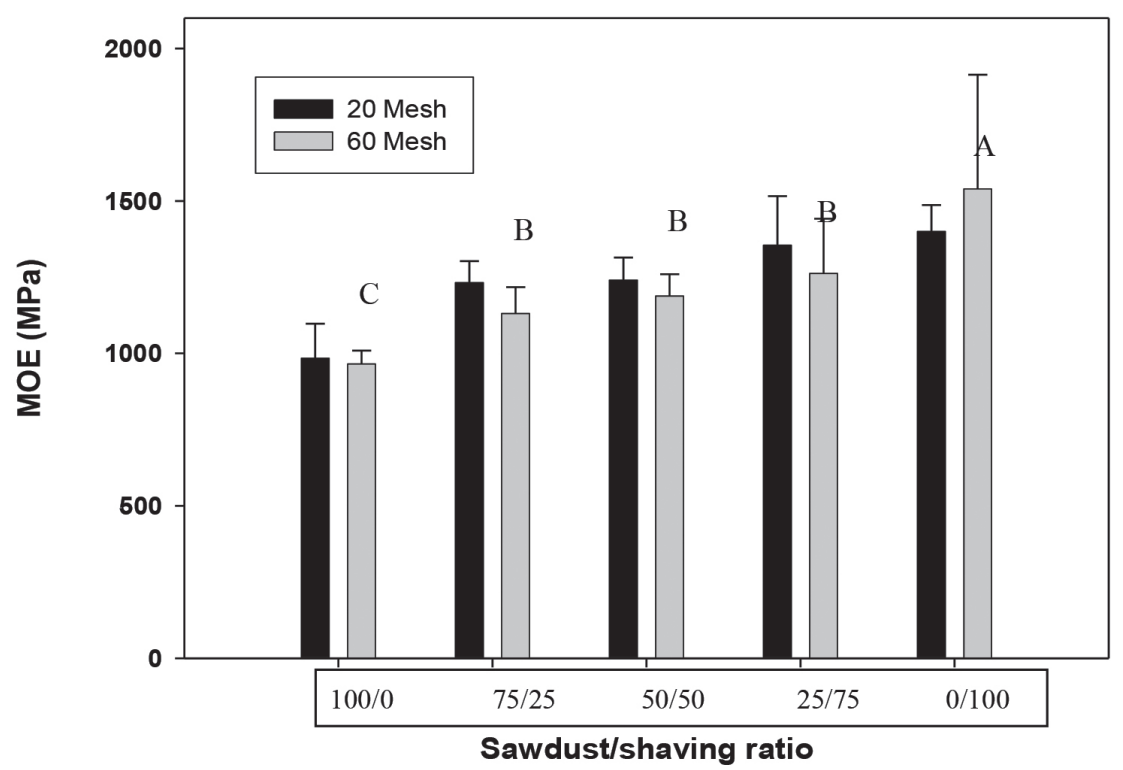

Figure 3. Effects of different wood flour formulations (\%) and mesh sizes on MOE values (letters on columns represents the Duncan groupings).

\section{Hardness}

Hardness was also improved as wood shavings content increased by $75 \%$ and then showed a decreasing trend (Figure 4). Statistical analysis revealed a significant direct relationship between the size of particles and hardness (Figure 4). In all sawdust/shaving ratios, smaller size particles (mesh 60) showed lower hardness than their larger counterparts. It is hypothesized that larger particles had better integration with the plastic matrix; nearly all mechanical properties approved this hypothesis, excluding some of the mixing ratios of the impact strength.

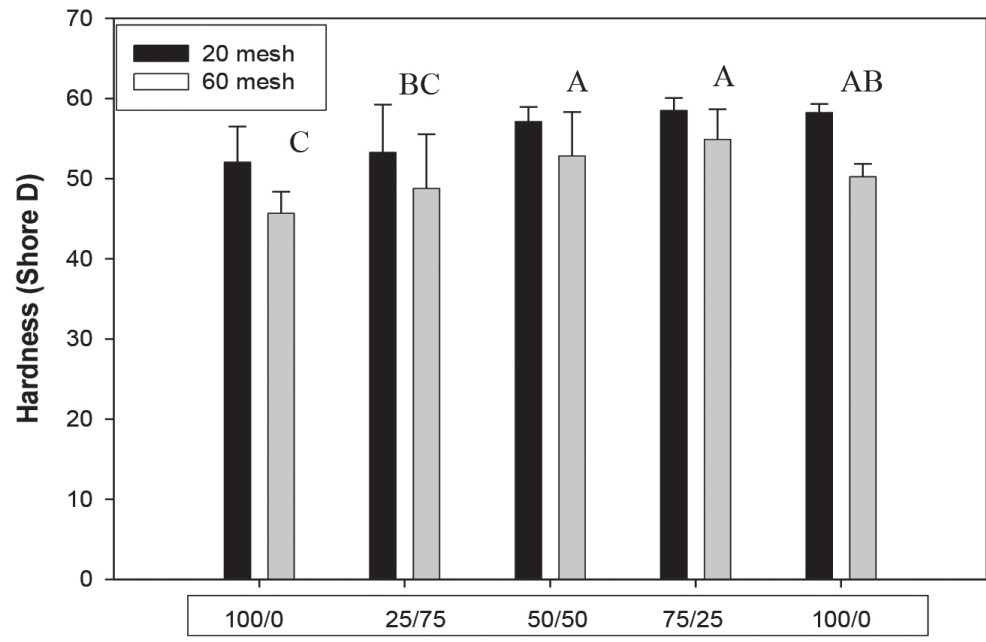

Sawdust/shaving ratio

Figure 4. Effects of different wood flour formulations (\%) and mesh sizes on hardness values (letters on columns represents the Duncan groupings). 


\section{Izod Unnotched Impact Resistance}

Unnotched impact strength represents the resistance of materials against crack initiation. The more the value is, the more energy the specimen absorbs (Steckel et al. 2007, Tajvidi and Takemura 2010). Impact resistance tests showed higher values in larger-size wood flour (mesh 20) when the sawdust content was higher (Figure 5). As the sawdust content decreased, impact resistance values wood flour with smaller size increased in comparison to wood flour with larger size. Reasons may be traced to the significant higher aspect ratio of small-size shavings (Table 2) in comparison to the other wood flours in the present study; that is, the high aspect ratio (1/d) resulted in the significant increase in the impact resistance of the small-size wood flour (mesh 60) with higher shaving content.

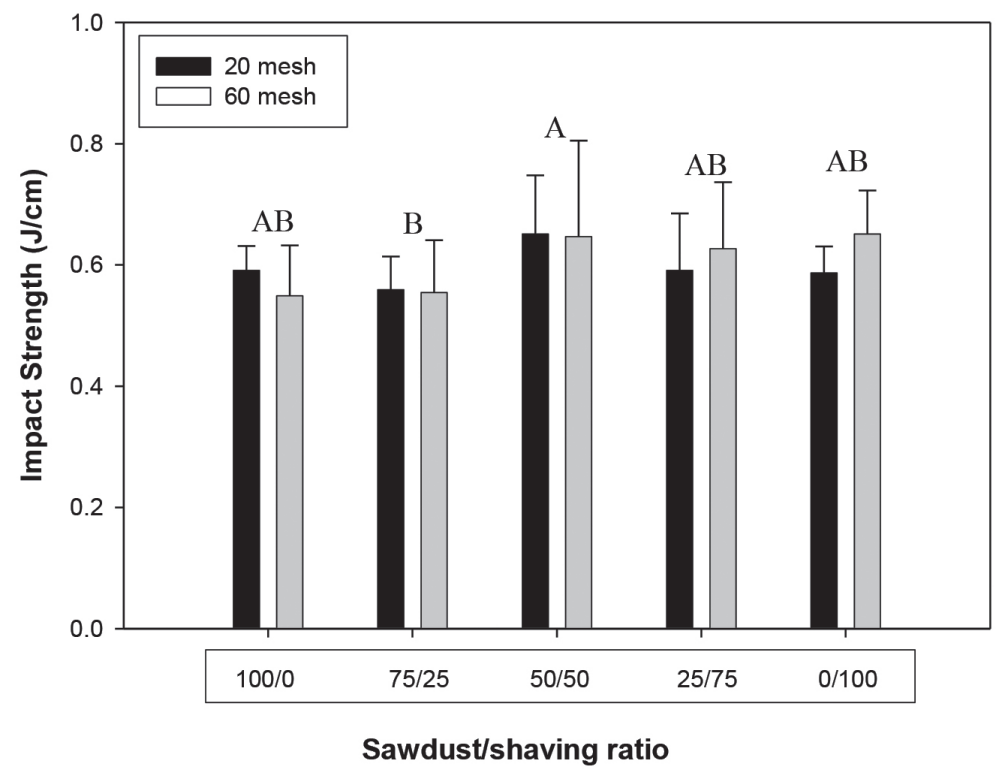

Figure 5. Effects of different wood flour formulations (\%) and mesh sizes on unnotched impact strength values (letters on columns represents the Duncan groupings).

\section{Physical Properties}

\section{Water Absorption}

Generally, all specimens, regardless of the treatment, absorbed more water at longer times. Comparing different treatments with the larger mesh size, it was observed that the increase in wood shaving content initially increased water absorption slightly, which was reduced at higher wood-shaving contents (Figure 6). In the smaller mesh size, however, formulations with $100 \%$ sawdust or wood shavings showed the same water absorption behavior (Figure 7); the maximum water absorption occurred in the formulation with $50-50 \%$ sawdust and wood shavings and all hybrid formulations exhibited increased water absorption. One more interesting observation was the fact that the effect of replacing parts of the wood flour with shavings had a more pronounced effect on water absorption when particle size was smaller. 


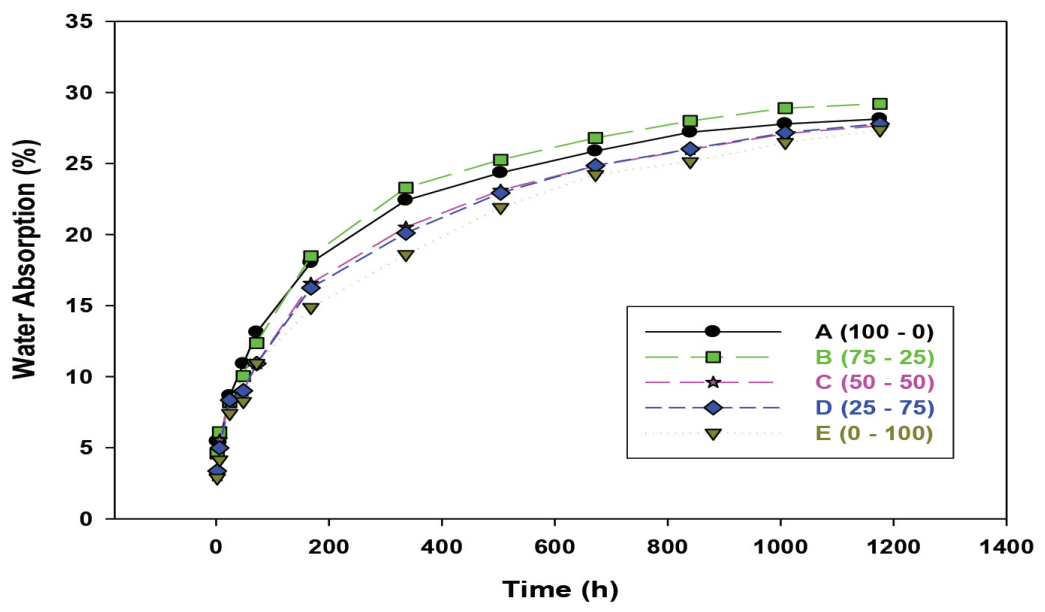

Figure 6. Long term water absorption of WPC panels made of beech 20 mesh wood flour and shavings.

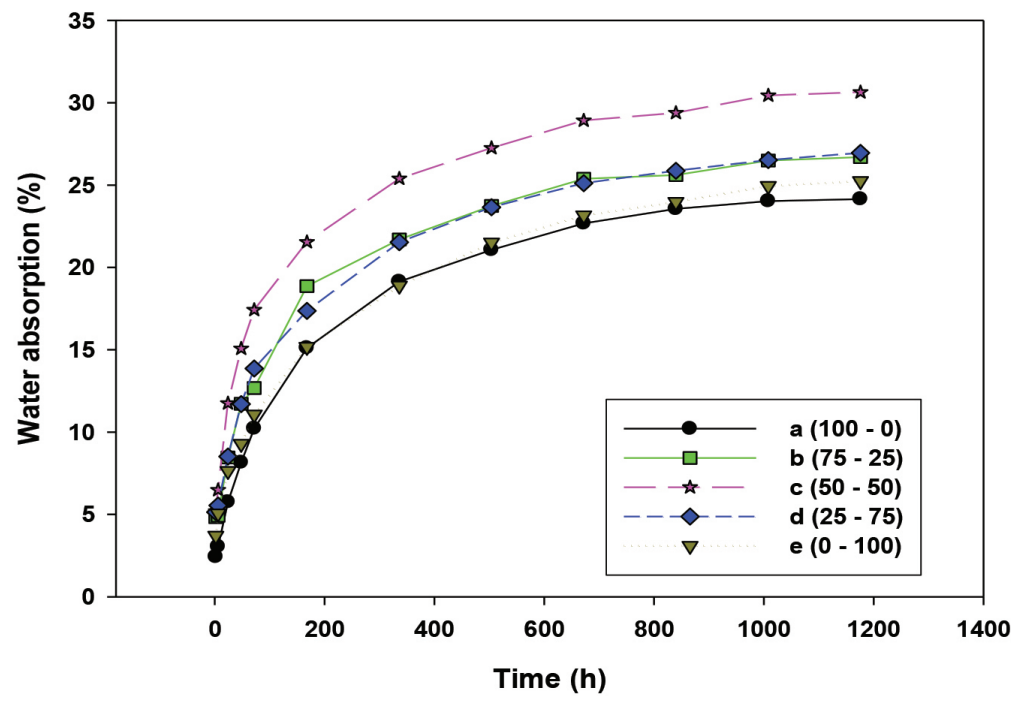

Figure 7. Long term water absorption of WPC panels made of beech 60 mesh wood flour and shavings.

\section{Thickness Swelling}

As the shaving content increased up to about 50 percent, the amount of long term thickness swelling (1400 hours) also increased in both mesh sizes (Figures 8 and 9). Higher shaving contents than $50 \%$ though did not result in any further increase in thickness swelling. Trends in thickness swelling showed a higher slope in WPC panels made of 20 mesh wood flour in comparison with those made of 60 mesh but leveled off faster as well.

Corner points showed faster thickness swelling in comparison with the center points at initial stages. As time went on, more thickness swelling occurred in corner points but it slowed down after a while so that thickness swelling showed nearly the same values in the center point and corner points at the end of the test. 
Due to the existence of density gradient in hot pressed composite materials, the surface layers have more density and less porosity, resulting in slower penetration of water molecules into the composite structure. This explains the faster thickness swelling of the corner points at the initial stage. Furthermore, corner points are less restricted by other parts of the specimen and therefore can swell more easily even at the same water absorption level.
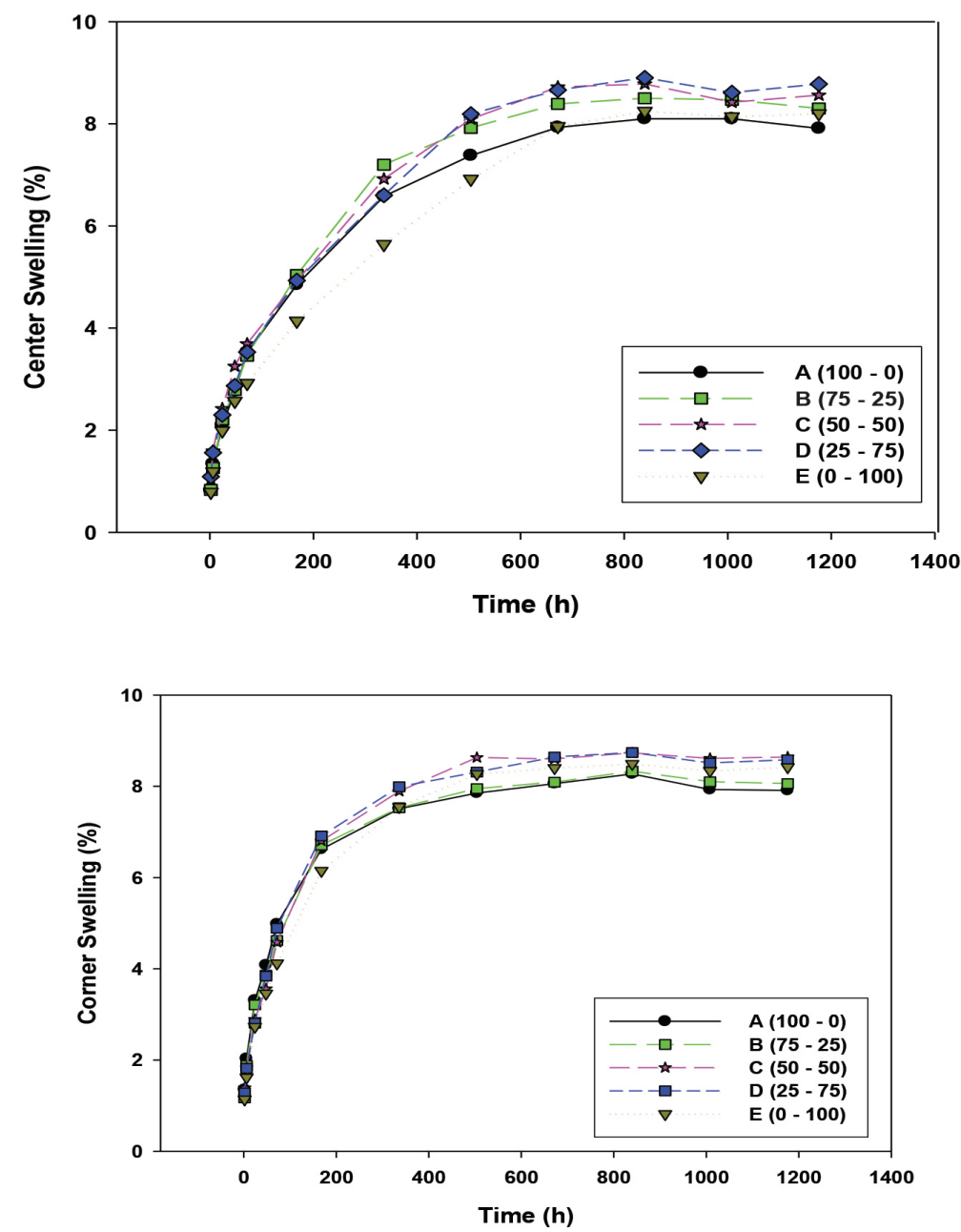

Figure 8. Long term thickness swelling in the center (left) as well as corner (right) points of 20 mesh WPC panels. 

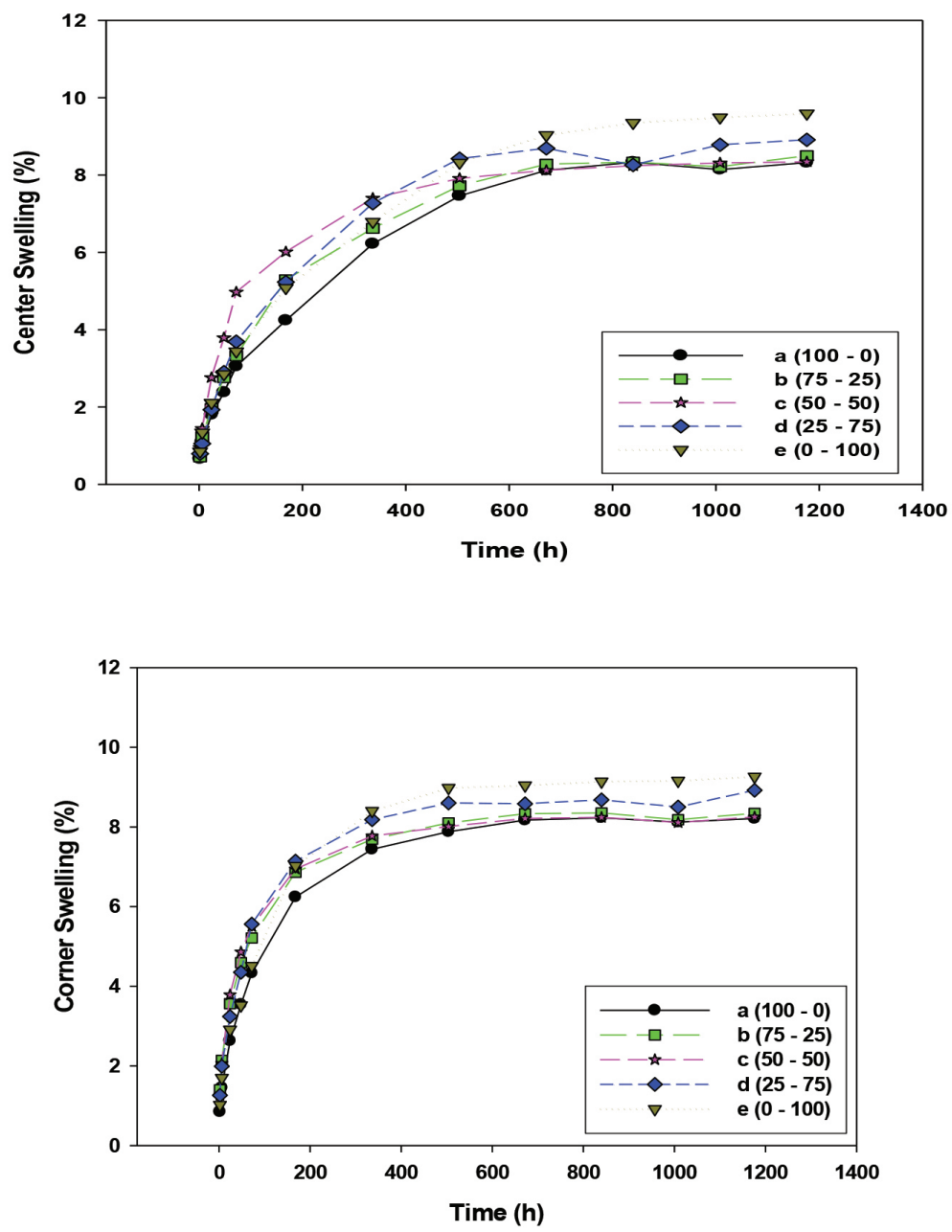

Figure 9. Long term thickness swelling in the center (left) as well as corner (right) points of 60 mesh WPC panels.

The results of water diffusion coefficients showed no clear trends between either the mixing ratio or the mesh sizes (Table 3). However, maximum water absorption generally decreased as particle size decreased (Table 3); larger particles tend to provide more voids in between them. As the bulk of water absorbed in flat pressed WPCs is absorbed into voids, water absorption is expected to be higher for larger particle. 
Table 3. Maximum water absorption and water diffusion coefficient for the 10 treatments.

\begin{tabular}{|l|c|c|}
\hline Treatments & $\begin{array}{c}\text { Maximum water } \\
\text { absorption (\%) }\end{array}$ & $\begin{array}{c}\text { Water diffusion } \\
\text { coefficient }\left(\mathrm{mm}^{2} \mathrm{~s}^{-1}\right) \\
\text { E-03 }\end{array}$ \\
\hline A (100-0) & 28,5 & 0,863 \\
\hline B (75-25) & 30 & 0,718 \\
\hline C (50-50) & 27,4 & 1,169 \\
\hline D (25-75) & 27,5 & 0,827 \\
\hline E (0-100) & 27,5 & 0,863 \\
\hline $\mathrm{a}(100-0)$ & 23,6 & 1,119 \\
\hline $\mathrm{b}(75-25)$ & 22,3 & 1,343 \\
\hline $\mathrm{c}(50-50)$ & 30,2 & 0,732 \\
\hline $\mathrm{d}(25-75)$ & 22,6 & 1,224 \\
\hline $\mathrm{e}(0-100)$ & 25 & 0,809 \\
\hline
\end{tabular}

Cluster analysis of the mechanical properties (Figure 10) showed that formulations A-20 and a-60 were rather closely clustered. Furthermore, all the other treatments were clustered based on the mesh sizes rather than the flour-type; that is, B-20, C-20, D-20, and E-20 were clustered closely, and b-60, c-60, d-60, and e-60 were also clustered rather closely. It may then be concluded that, from a general point of view, WPC panels made of only sawdust would not exhibit proper mechanical properties. It may also be concluded that mesh size would not significantly affect the final values of mechanical properties if only sawdust is used. However, when a mixture of sawdust with ground shavings is used, the final results would be more influenced by mesh-size than the mixing ratio.

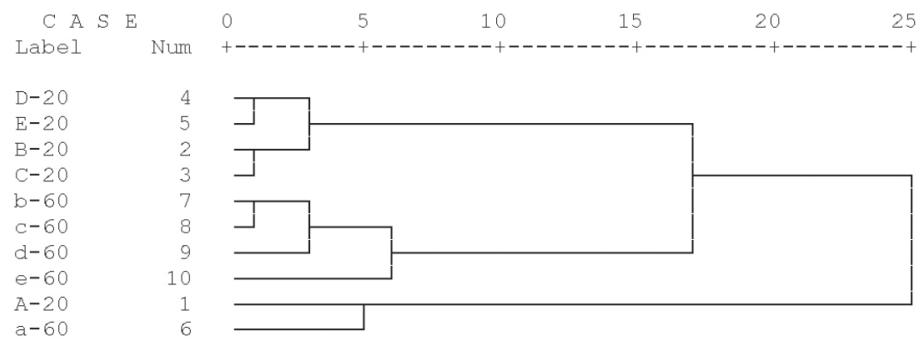

Figure 10. Cluster analysis of the 10 treatments, based on the mechanical properties (MOR, MOE, impact strength and hardness).

Cluster analysis of the 10 combinations based on the physical properties (TS and WA) showed significant differences between A-20 and a-20 treatments (Figure 11). This indicates that from a physical point of view, mesh size would make a greater difference than flour type when $100 \%$ of the flour is made up of sawdust. However, no particular trend was observed between treatments when a mixture of both sawdust and shavings was used in the production of WPC panels.

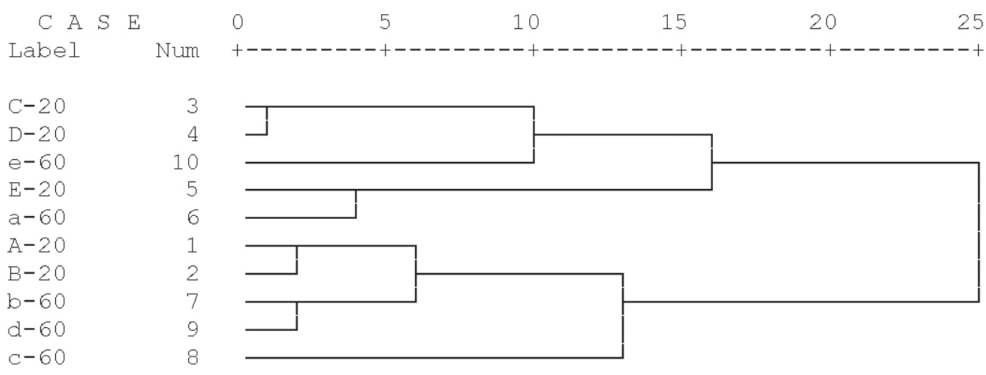

Figure 11. Cluster analysis of the 10 treatments, based on the physical properties (WA at 2, 24, and 1400 hours; and TS at 2, 24, and 1400 hours, both measured at centers and corners). 


\section{CONCLUSIONS}

Effects of wood flour with different mesh-sizes and types on the physical and mechanical properties of WPC-panels were studied here. Based on the results obtained from the present study, it may be concluded that the type and size of wood flour greatly affect the physical and mechanical properties of WPC. The mechanical properties of panels were significantly lower when $100 \%$ sawdust was used, regardless of what the mesh-size was used. This was attributed to higher aspect ratio of ground wood shavings as compared with the sawdust. While no trends were observed for water diffusion coefficients across treatment, larger particles resulted in on average higher maximum water absorption values.

In general, the panel made of 50\% wood flour combined with 50\% ground shavings exhibited overall suitable properties for most applications.

\section{ACKNOWLEDGMENT}

Authors are grateful to Mr. Peyman Kashani, from the Institute of Standard and Industrial Research of Iran (ISIRI), for the procurement of the standard test methods.

\section{REFERENCES}

Akhtari, M.; Ghorbani-Kokandeh, M.; Taghiyari, H.R. 2012. Study on the mechanical properties of Paulownia wood impregnated with silver, copper, and zinc oxide nanoparticles. Journal of Tropical Forest Science 24(4): 507- 511.

Ayrilmis, N.; Candan, Z.; White, R. 2007. Physical, Mechanical, and Fire Properties of Oriented Strandboard with Fire Retardant Treated Veneers. European Journal of Wood and Wood Products 65: 449- 458 .

Berger, M.J.; Stark, N.M. 1997. Investigations of species effects in an injection molding grade wood filled polypropylene, In: Proc. Woodfiber-Plastic Composites Conf. Forest Prod. Soc., Madison, Wis.

Chaharmahali, M.; Kazemi-Najafi, S.; Tajvidi, M. 2005. Mechanical properties of wood plastic composites made from particleboard and MDF wastes and polyethylene (HDPE) waste. Iranian Journal of Wood and Paper Science Research 20(2): 271-284.

Chaharmahali, M.; Kazemi-Najafi, S.; Tajvidi, M. 2007. Effect of Blending Method on the Mechanical Properties of Wood-Plastic Composites. Iranian Journal of Polymer Science and Technology 20(4): 361-367.

Chaharmahali, M.; Tajvidi, M.; Kazemi-Najafi, S. 2008. Mechanical Properties of Wood Plastic Composite Panels Made From Waste Fiberboard and Particleboard. Polymer Composites 29(6): 606-610.

Chaharmahali, M.; Mirbagheri, J.; Tajvidi, M.; Kazemi-Najafi, S.; Mirbagheri, Y. 2010. Mechanical and Physical Properties Wood-Plastic Composite Panels. Journal of Reinforced Plastics and Composites 29(2): 310-319.

Eshaghi, S.; Faezipour, M.; Taghiyari, H.R. 2013. Investigation on lateral resistance of joints made with drywall and sheet metal screws in bagasse particleboard and comparison with that of commercial MDF. Maderas: Ciencia y Tecnología 15(2): 127-140. 
Gallagher, L.W.; McDonald, A.G. 2013. The effect of micron sized wood fibers in wood plastic composites. Maderas: Ciencia y Tecnología 15(3): 357-374.

Lee, B.J.; McDonald, A.G.; James, B. 2001. Influence of fiber length on the mechanical properties of wood fiber/polypropylene prepreg sheets. Material Research Innovations 4(2-3): 97- 103.

Myers, G.E.; Chahyadi, I.S.; Coberly, C.A.; Ermer, D.S. 1991. Wood flour/polypropylene composites: influence of maleated polypropylene and process and composition variables on mechanical properties. Int J Polymeric Matter 15:21- 44.

Papadopoulos, A. 2012. Sorption of acetylated pine wood decayed by brown rot, white rot, and soft rot: different fungi - different behavior. Wood Science and Technology 46: 919- 926.

Stark, M.N.; Berger, J.M. 1997. Effect of Particle Size on Properties of Wood-Flour Reinforced Polypropylene Composites, The fourth Intl. Conference on Woodfiber-Plastic Composites, Madison, Wisconsin, pp. $134-143$.

Stark, N.M.; Rowlands, R.E. 2003. Effects of wood fiber characteristics on mechanical properties of wood/polypropylene composite. Wood and Fiber Science 35(2):167-174.

Steckel, V.; Clemons, C.M.; Thoemen, H. 2007. Effects of materials parameters on the diffusion and sorption properties of wood-flour/polypropylene composites. Journal of Applied Polymer Science 103(2):752-763.

Stockel, F.; Konnerth, J.; Moser, J.; Kantner, W.; Gindl-Altmutter, W. 2012. Micromechanical properties of the interphase in pMDI and UF lines. Wood Science and Technology 46: 611- 620.

Taghiyari, H.R.; Enayati, A.; Gholamiyan, H. 2012. Effects of nano-silver impregnation on brittleness, physical and mechanical properties of heat-treated hardwoods. Wood Science and Technology 47(3): 467- 480.

Tajvidi, M.; Haghdan, S.; Kazemi-Najafi, S. 2008. Physical properties of novel layered composites of wood flour and PVC. Journal of Reinforced Plastic and Composites 27(16): 1759- 1765.

Tajvidi, M.; Kazemi-Najafi, S.; Moteei, N. 2006. Long-term water uptake behavior of natural fiber/ polypropylene composites. Journal of Applied Polymer Science 99: 2199- 2203.

Tajvidi, M.; Takemura, A. 2010. Thermal degradation of natural fiber-reinforced polypropylene composites. Journal of Thermoplastic Composite Materials 23 (3): 281- 298.

Valenzuela, J.; von Leyser, E.; Pizzi, A.; Westermeyer, C.; Gorrini, B. 2012. Industrial production of pine tannin-bonded particleboard and MDF. European Journal of Wood and Wood Products 70: 735-740.

Zaini, M.J.; Fuad, M.Y.A.; Ismail, Z.; Mansor, M.S.; Mustafah, J. 1996. The effect of filler content and size on the mechanical properties of polypropylene/oil palm wood flour composites. Polymer Int 40 (1):51-55. 